\title{
Estudos sobre tuberculose
}

\author{
pelo \\ Dr. A. FONTES
}

Chefe de serviço do Inotituto Oswaldo Cruz

(Corn a estampa 32.)

Toxidez da tuberculina.

Compreende-se que a tuberculina antiga seja toxica por ser um produto complexo, derivado do metabolismo bacteriano em um meio rico en albuminoides.

Basta a desintegração da molecula albuminoide, quando mais não seja senão como produto de sua autolyse, pàra que se reconheça a toxidez de um caldo de cultura. Independente disso, entretanto, a cultura de tuberculose é o fator preponderante na toxidez da tuberculina, pois que, mesmo na ausencia de caldos de cultura, lidando-se somente com os produtos extraidos dos bacilos, produzern-se as mesmas reações biolojicas que as obtidas com os caldos tuberculinicos,

Donde deriva a ação toxica? A quimica do bacilo é complexa. Ao lado de substancias de natureza albuminoide encontram-se no interior do corpo bacilar lipoides, acidos graxos de gorduras neutras, cêras etc. Os trabalhos de MUCH \& LESCHKE mostram que a emulsão bacilar contem albumina, gordura (acidos graxos, lipoides e gorduras neutras), veneno e substancia odorante.

\section{Hipersensibilidade na tuberculose}

Sabemos que com qualquer dessas substancias se póde determinar uma reação de hipersensibilidade e, com algumas delas, se póde produzir o schock anafilatico que acarreta a morte do animal.

WHITE \& AVERY atribuem a uma toxiproteina, obtida pelo metodo de VAUGHAN, a função toxica no veneno tuberculoso, pois que com ela conseguem determinar a anafilaxia em cobaias e, em outro trabalho, WHITE nega mesmo aos lipoides bacilares qualquer propriedade hipersensibilisante. THIELE \& EMBLETON, entretanto, concluem de sua experimentação que os fosfatides do bacilo da tuberculose podem provocar a formação de anticorpos (precipitinas, BORDET-GENGOU, anticorpos anafilaticos). Experimentaram estes autores com produtos isentos de albuminoides, o que verificavam pela reação da ninhidrina.

Os proprios trabalhos de MUCH \& LESCHKE mostram que: "a reação da tuberculina não é uma reação uniforme, mas depende das diversas substancia que a compoem. Tanto as substancias albuminoides quanto 
as substancias graxas, assim como as toxinas dissolvidas e volateis do virus da tuberculose podem provocar uma reação de hiperensibilidade".

Os trabalhos de THIELE \& EMBLETON mostram ainda que os fosfatides do Bacilus tuberculi podem tornar cobaias hipersensiveis não sj́ a essas mesmas substancias, como ainda ás proteinas do bacilo, com uma sintomatolojia identica á que ocorre com a anafilaxia aguda, determinada pela proteina especifica. A reciproca é tambem verdadeira. As cobaias sensibilisadas pela proteina bacilar reajem anafilaticamente aos fosfatides especificos.

MUCH \& LESCHKE pensam ainda que a reação tuberculinica varia de individuo ;ara individuo. Em alguns casos ela é uma reação que se passa entre albumina e anti-albumina, em outros entre gordura e anti-gordura, em outros ainda entre toxina e anti-toxina. Além disso, em outros individuos, diversos desses componentes podem ajir simultaneamente, de modo que todos os casos possiveis de variação, por calculo, se podem apresentar.»

\section{Hipersensibilidade ou anafilaxia.}

As perturbações da vida somatica no organismo tuberculoso se afastam ainda das reações conhecidas geralmente e mais propriamente com o nome generico de anafilaxia.

O proprio FRIEDBERGER e seus colaboradores (apud LESCHKE, op. cit,) mostram "que na hypersensibilidade á albumina, quantidades pequenas de albumina provocam febre na re-injeção e quantidades maiores acarretam a morte acompanhada de colicas, queda de temperatura, desaparecimento do complemento e flatulencia pulmonar. $\mathrm{Na}$ hipersensibilidade á tuberculina, pequenas quantidades de tuberculina produzem tambem febre (reação geral), ao passo que quantidades maiores causarn a morte acompanhada de queda de temperatura. Faltam aqui, porém, a flatulencia pulmonar e o desaparecimento do complemento; aléın disso, a queda da temperatura não é tão aguda cơno na hipersensibilidade á albumina".
Uma outra prova da diversidade desses estados se tira da observação de tratamentos tuberculinicos mal dirijidos. Emquanto que pels ação de antijenos que se adicionam a toxojeninas formando apotoxinas (RICHET); de sensibilisinas e sensibilinojeno (BESREDKA): de coagulinas e de lysinas (NICOLLE): do grupamento toxico da albumina (VAUGHAM \& WHEELER); da substancia peptoniforme (KRAUS \& BIEDDL); do derivado alexico (DOERR), citados por BESREDKA; do anticorpo toxojenico (ALCANTARA GOMES) - pela ação de qualquer desses principios hipoteticos-se determina o schok anafilatico, nos individuos tratados pela tuberculina, as manifestações de um emprego intempestivo se traduzem pelas reações de fóco $s_{e m}$ os fenomenos determinantes da morte brusca.

Poderia essa diferença correr por conta da velocidade da reaçâo, como BESREDKA, acredita se dar na pratica da imunisação anti-anafilatica.

Pelo exposto se vê, pois, que na infeção tuberculosa se manifesta um estado especial de hipersensibilidade aos venenos do virus que não é identico aos estados conhecidos $\mathrm{em}$ biolojia pela designação de anafilaticos e para cuja explicação as teorias propostas não fornecem razões que satisfaçam de modo cabal.

\section{Hipersensibilidade, fenomeno da reação celular autonoma $e$ individual.}

Creio poder presumir que esse estado de hipersensibilidade é a expressão de uma modalidade reacionaria, inteiramente especial á celula sensibilizada que reaje individualmente e de modo autonomo. A seguinte observação parece isso demonstrar.

$\mathrm{Na}$ clinica hospitar do Exmo. Snr. Prof. REGO LOPES apresentou-se um doente com uma lesão tuberculosa ocular, cujo diagnostico clinico fôra confirmado por uma cutireação positiva (v. PIRQUET). Após ter cessado o periodo reacionario foi instituido o tratamento tuberculiuico, enn cujo decurso se manifestou intensa reação, traduzida por um psoriasis do antebraço onde dous mezes antes 
se havia praticado a reação diagnostica, e pela revivecencia da reação especifica.

$\mathrm{Da}$ intensidade da reação havida a figura junta dá poderoso testemunho. Assim o organismo tuberculoso, não obstante ser localizada a infeção, reajiu primeiramente pela cuti-reação; a tuberculinizaçăo do paciente determinou uma hipersensibilidade das celulas que anteriormente haviam reajido e cuja reação cessara dous mezes antes, permitindo uma reativação da modalidade reacionaria, que se mostrou então mais intensa que da primeira vez, e o aparecimento duma lesão nova (psoriasis).

A diferença reacionaria nesse ante-braço por elementos celulares da mesma natureza, solicitados pelo mesmo principio toxico, não encontra explicação facil e mostra que celulas do mesmo tecido, no mesmo individuo, solicitadas pelo mesmo toxico, podem agir de modo autonomo, individualmente $e$ diversamente.

\section{Atenuação ou destruição dos venenos hipersensibilisantes? \\ Tuberculinoterapia ou soroterapia antitu- berculosa? \\ Imunidade antituberculinica.}

De ha muito veem os investigadores se preocupando com a possibilidade de destruir ou atenuar $o$ poder hipersenslbilisante dos venenos tuberculinicos. As investigações tendentes á obtenção de sôros nitidamente antitoxicos, pelas dificuldades do seu preparo, pela inconstancia de sua produção e pela diverjencia dos resultados obtidos em inãos de experimentadores competentes, mostram não ser essa a via promissôra, pelo menos no momento atual, para a terapeutica especifica.

E' verdade já adquirida que os fenomenos de imunidade artificial em tuberculose existem de fato, mas são eles de tal sorte inconstantes e de tão dificil obtenção que na pratica corrente, tudo faz crer serem de valor pouco seguro.

Entretanto o mesmo não se póde afirmar de modo tão categorico em relação a imunisação ativa anti-tuberculinlca do organismo tuberculoso.
A tuberculinoterapia sem ser a solução ideal, pelo menos como os clinicos querem compreender o problema terapeutico, esperando desse metodo ação rapida, eficaz e permauente, satisfaz comtudo as duas ultimas condições, não podendo satisfazer á primeira, pela propria natureza do seu efeito, deterninante duma imunisação ativa, de resultado tardio consequente ás reações organicas. E' pois esse metodo e de acordo com os fatos que regulam os processos biolojicos da cura, $o$ que mais vantajens oferece na pratica terapentica.

Para isso bem compreender é preciso que partamos do principio verdadeiro que a tuberculose é uma infeção de marcha cronica, que, ás mais das vezes, permite ao organismo lutar vantajosamente contra a toxiemia. A tuberculinoterapia tem pois por escopo principal determinar um estado de imunidade relativa do organismo tuberculisado aos venenos bacilares, oriundos dos fócos de infeção. Os elementos nobres do organismo ficam insensiveis a eles de tal sorte que pode assim ser atinjido o acmé da defeza organica com a expulsão ou enquistamento do fóco tuberculoso. A imunisação tuberculinica oferece, porém, o perigo de hipersensibilização do paciente quando seu emprego é intempestivo, ou, mesmo em casos especiais, por motivos ainda desconhecidos, mas que estão intimamente ligados ás propriedades dos venenos ditos anafilat:santes.

Daí as investigações tendentes á neutralização ou destruição desses toxicos. LOEWENSTEIN e PIRQUET foram os primeiros que observaram a desintoxicação da tuberculina pela adição de sôro de individuos tuberculosos, reconhecendo assim a existencia de anticorpos. Esses autores pensam que a neutralização só é possivel com sôro de individuos tuberculosos.

WHITE \& GRAHAM verificam comtudo que a neutralisação se dá tambem com o sôro de individuos normais que mostra entretanto capacidade de neutralisação menor que o dos individuos tuberculosos. Nestes sôros, comtudo, tambem se póde notar a ausencia de corpos neutralizantes. 
As ideas de LOEWENSTEIN e PIRQUET foram corroboradas pelos trabalhos de outros autor:s, entre os quais pelos de ALBAHARY, que, estudando as toxalbuminas da tuberculina observou que estas sofrem uma alteração de sua ação fisiolojica em presença de sôro sanguineo. Uma serie de ensaios mostrouthe que o sôro sanguineo influe sobre a tuberculina de tal maneira que esta ultima perdia tanto mais de sua força reativa sobre animais infetados com tuberculose, quanto mais tempo ele deixava dijerir a mistura de tuberculina e sôro sanguineo (em condiçóes asepticas).-Desse fato ele concluiu que o sôro sanguineo continha determinadas substancias que possuiam ação neutralisante sobre as toxalbuminas da tuberculina.

$\mathrm{Em}$ seus primeiros ensaios empregou a tuberculina de Koch misturada com a mesma quantidade de sôro sanguineo centrifugado, posta a mistura a dijerir durante 3 a 4 dias en lugar escuro e quente $\left(20^{\circ}\right)$. Para exaninar a sua toxidez todos os 3 dias fazia uma injeção de 1 cc. desta mistura em 3 cobaias. A mesma experimentação ele repetiu substituindo o sóro de sangue de animal são pelo sôro de sangue de animais tuberculosos $\mathrm{e}$ constatou resultados quasi iguais, que the permitiram concluir que tanto a mistura de tnberculina e sôro de animal são como a de tuberculina e sôro de animal tuberculoso não provocam efeito notavel em animais sãos, apenas pareceu-lhe que as cobaias que receberam tuberculina e sôro tuberculoso sofriam mais no principio que os outros e mostravam menos apetite.

Algum tempo depois o autor repetiu esses ensaios (1907-1910, op. cit.) e verificou que os animais tuberculosos inoculados com tuberculina e sôro normal morreram da infeção nos 2 a 8 mezes que se seguiam, ao passo que do grupo tratado com tuberculina e sôro tuberculoso um animal morreu depois de 6 mezes e os dois outros ainda viviam un ano mais tarde. Por autopsia esses animais mostravain um notavel hipertrofia ganglionar, parecendo comtudo os pulmões e figado normais.
Estes resultados fizeram-ı'o suspeitar duma ação imunisante da mistura de tuberculina e sôro tuberculoso e, em seguida, começou a fazer ensaios sistematicos com este preparado a que ele denominou "tuberculina sensibilizada". No correr de novos ensaios chegou o autor á convição que a tuberculina sensibilizada, quando inoculada na cobaia em pequenas quantidades, durante $2-3$ semanas, póde atrazar a infeção tuberculosa; se, porém, forem esses animais sujeitos durante $2-3$ mezes á açăo dessa vacina em injeções regulares de pequenas dóses da mistura a $10 \%$, podem eles chegar a uma imunidade muito consideravel. Assim, pensa o autor que "a tuberculina sensibilizada, se ela é o antijeno da tuberculose, deve, quando inoculada em animais sensiveis, neles provocar sintomas desta molestia, de acordo com a lei fisiolojica universal, conforme a qual uma imunidade ativa só póde ser obtida depois de realizadas manifestações patolojicas".

Para isso verificar $\mathrm{cm}$ colaboração com $o$ Snr. J. E. DUMONT, injetou 2 cc. de tuberculina sensibilizada no pescoço dum touro de 630 quilos, que não reajira á tuberculina pura e que pelo exame veterinario se mostrara completamente são. A temperatura media do animal que orçara entre 38,3 e 38,4 , se elevou depois de 10 horas a $38^{\circ}, 9$ e permaneceu assim durante 12 horas mais ou menos. $O$ animal, apezar de conservar o apetite, mostrara-se com o pêlo erriçado e os olhos turvos. No dia seguinte a temperatura caiu a 38,1 , e o animal parecia de novo normal. Uma segunda injeção duma dóse um pouco mais forte não produziu efeito eșpecial; na terceira injeção, porém, realizada 48 horas depois, a temperatura de novo subiu 0,9 , para baixar depois de 10 horas a 37,9 ; durante este tempo o touro dá a impressão dum animal infetado; conjestão pulmonar com tosse, respiração acelerada, falta de apetite (as fezes eram to(lavia normais), manifestaç9cs essas que depois de 18 horas retrocederam. O animal foi abatido e por autopsia se reconheceu que todos os orgãos estavam normais.

Acreditando, portanto, que a tuberculina sensibilizada seja realmente o antijeno da 
tuberclilose, o autor examinou em seguida sua ação sobre animais infetados e simultaneamente, em colaboração com o Dr. VASSAL, sujeitou um tuberculoso em segundo periodo com larinjite aguda, a um processo de auto-vacinação, se utilizando de tuberculina Beraneck e serosidade obtida por ação de vesicatorio.

Conjuntamenfe administrava extratos glandulares anti-toxicos. Os resultados foram concludentes, nesse e em dois outros casos, em quanto que em cobaias tuberculosas não obteve resultado, o que pensa ter sido devido a ter empregado apenas a tuberculina sensibilizada por sôro humano, portanto tuberculina sensibilizada heterojenea. Assim, termina o autor o seu artigo, pensando poder adınitir que "a tuberculina sensibilizada por sôro de individuos tuberculosos, possue uma ação imunisante, mas que para a cura da tuberculose é necessaria tuberculina sensibilizada por sôro individual":

Entre nós, ALCANTARA GOMES defende e desenvolve teorias baseadas em experiencias analogas a essas, propondo um metodo terapeutico, por ele denominado "tisiovacina'-.

SPENGLER atribue aos seus "Immuenkoerper" (I. K.) propriedades especiais baseadas na existencia de tuberculo-precipitina encerrada, segundo o seu pensar, em hematias. Enorme copia de trabalhos demonstra contudo, senão a ineficacia, pelo menos a grande inconstancia desse processo.

Entre os autores italianos BRUSCHET. TINI tenta resolver o problema terapeutico apresentando sua vacina sensibilizada (sôrovacina), BERTARELLI \& DALTA constatam que os coelhos são susceptiveis de adquirirem uma imunidade á tuberculina, cujas injeções conferem ao sôro desses animais propriedades antitoxicas, capazes de fazerem desaparecer a reação febril que a tuberculina provoca em cobaias tuberculosas.

Essas opiniões são corroboradas pela generalidade dus autores que se têm ocupado do assunto e, seria demais fastidioso continuarmos as citações nesse sentido. Colije-se pois, do que acima ficou exposto que:
A tuserculina póde determinar por inoculações repetidas em animais sensiveis, sãos ou tuberculosos, um estado de imunidade RELATIVA, que se traduz pela existencia no sôro desses animais de substancias que se opoem $a$ sua função hipersensibilisante.

\section{Natureza quimica daz substancias neu- tralizadoras.}

Qual será entãu a natureza quimica dessas substancias neutralizadoras?

Resulta da observação de todos quantos se têm ocupado do assunto que a adição de substancias especiais denominadas lipoides aos venenos dos virus em geral, e, em determinadas condições, aos do virus da tubercu. lose, atenua as reações de hipersensibilidade por eles produzidas, ou mesmo afastam-n'as, de modo a não serem percebidas.

As primeiras experimentações feitas por WASSERMANN e TAKAKI, referidas por BANO com a toxina tetanica e emulsão de cerebro e medula, permitiram a esses autores concluir que a neutralisação da toxina se dá pela sua ligação á cerebrona, constituindo um complexo atoxico. Constatou ainda TAKAKI que os imuni-sôros mostranı uma maior percentajem em lipoides do que sôros normais.

Em relação á fixação do complemento, não obstante não ser esta reação das mais sensiveis para a verificação da infeção, notase contudo uma certa dependencia entre os lipoides no sôro do sangue experimentado e o antijeno usado.

Os anti-rorpos graxos estudados por MUCH (apud LOESCHKE op. cit.) mostram a possibilidade da obtenção de anti-corpos especificos ás substancias graxas que se formam com mais segurança nos organismos infetados que nos organismos sãos. Mesmo in vitro, pode ser verificada a influencia de substancias ricas em lipoides, como o oleo de figado de bacalhau, sobre o fenomeno da fixação do complemento. E' o que se deduz da experimentação que fizemos, transcrita nas tabelas I e II. 
Empregavamos como antigeno a tuberculina T. O. A. (caldo de cultura dos bacilo humano, filtrado em vela de porcelana). lecitina em mistura com tuberculina antiga que deixava permanecer em contato durante muitas horas em estufa. Utilizando depois

\section{TABELA I}

Serie feita com emulsão de oleo posta emn contacto com a tuberculina no momento de se proceder á reação.

$\mathrm{O}$ veiculo usado foi sempre agua fisiolojica a $9 \%$.

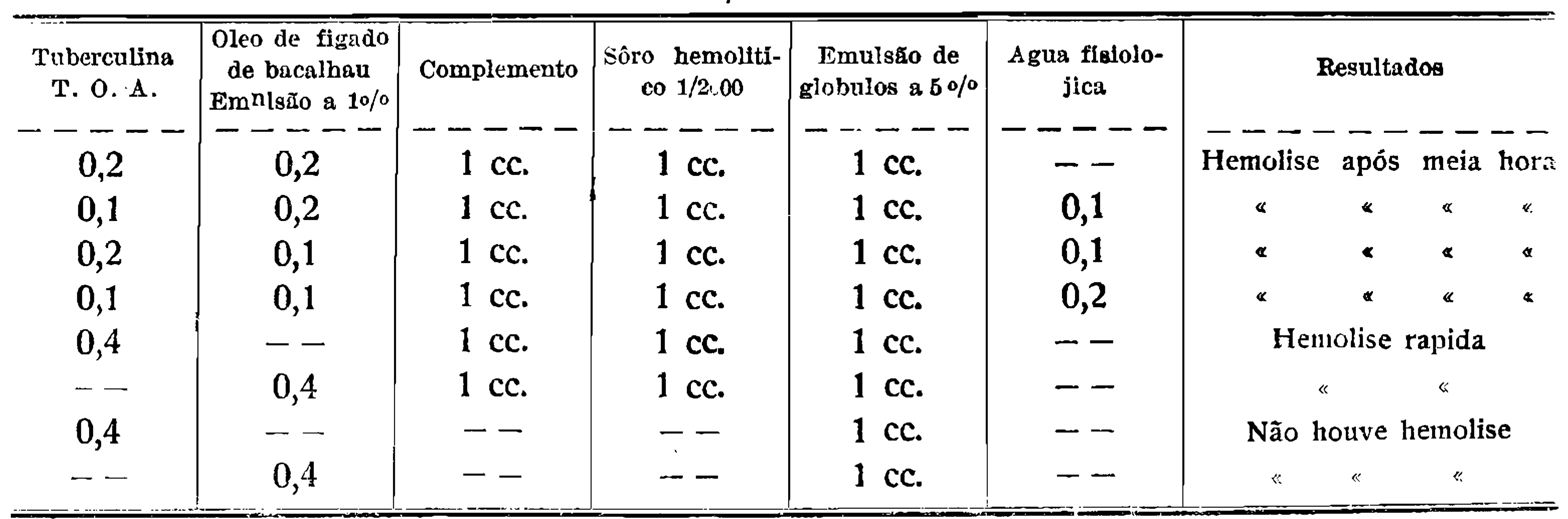

\section{TAELA II}

Serie feita com tuberculina saturada por oleo de figado de bacalhau, tendo o oleo permanecido em contato com a tuberculina cerca de 24 horas a $37 \circ \mathrm{C}$.

\begin{tabular}{|c|c|c|c|c|c|c|c|}
\hline $\begin{array}{l}\text { Tuberculina } \\
\text { saturada }\end{array}$ & $\begin{array}{c}\text { Tuberculina } \\
\text { pura }\end{array}$ & $\begin{array}{c}\text { Agua satura- } \\
\text { da de oleo }\end{array}$ & Complemento & $\begin{array}{c}\text { :ôro hemoli- } \\
\text { tíco }\end{array}$ & Globulos & $\begin{array}{c}\text { Agua fisiolo- } \\
\text { jica }\end{array}$ & Resultados \\
\hline--- & $---\cdots$ & ---- & $-\cdots-$ & ---- & ---- & --- & $--\cdots--\cdots$ \\
\hline 0,1 & -- & -- & $1 \mathrm{cc}$. & $1 \mathrm{cc}$. & $1 \mathrm{cc}$ & 0,3 & Fixação parcial \\
\hline 0,2 & -- & $-\rightarrow$ & 1 cc. & $1 \mathrm{cc}$. & 1 cc. & 0,1 & Fixação forte \\
\hline 0,4 & -- & -- & 1 c. & 1 cc. & $1 \mathrm{cc}$. & -- & * \\
\hline-- & 0,2 & $-\infty$ & $1 \mathrm{cc}$. & $1 \mathrm{cc}$. & 1 c.. & 0,2 & Hemolise \\
\hline-- & -- & 0,2 & $1 \mathrm{cc}$. & $1 \mathrm{cc}$ & 1 c.. & 0,2 & « \\
\hline
\end{tabular}

A experimentação exposta parece indicar haver necessidade de contato mais prolongado entre o oleo (provavelmente entre os lipoides do oleo) e a tuberc:-lina para que a fixação do complemento se dê.

No tocante aos venenos tuberculinicos BEYER constatou, de acôrdo com as ideas de CALMETTE (cit. por BEYER) que a lecitina tinha a propriedade de evitar a reação tuberculinica em individuos tuberculosos. Para esse fim empregou BEYEF, uma emulsão de essa mistura por via cutanea, hipodermica ou conjuntival, os resultados foram incertos.

LEMOINE e GERARD estudam a ação antitoxica e anti-bacilar dos lipoides en trabalhos confirmados posteriormente por ISCOVESSO, CHAUFFARD e GRIGAULT, EHRLICH, FERMI, PRIBRAM, RAUBITSCHECK (cit. por LEMOINE) um d'elles verifica (LEMOINE) que os lipoides biliares neutralisavam a tuberculina a ponto de impedir os fenomenos de ocılo ou de cuti-reação de se 
produzirem em quasi a totalidade dos casos, porém não em todos.

Repetindo esses estudos entre nós constatámos que não só a lecitina como a colesterina exercem ação antitoxica em relação á tuberculina; ou digamos melhor, exercem ação impeaiente á reaçâu" tuberculinica.

Os mesmos resultados foram obtidos saturando a tuberlina com gema de ovo ou com oleo de figado de bacalhau e com bile. A experiencias procedidas ccm a tuberculina que assim preparámos foram feitas no Hospital de $S$. Sebastião pelo Exmos Snrs. Drs. JULIO MONTEIRO e PIRES SALGADO, na Polyclinica do Rio de Janeiropelo Exmo. Snr. Dr. DIONISIO CERQUEI, RA, DD. Chefe de Laboratorio do Serviço do Exmo. Snr. Prof. ALOYSIO DE CASTRO e na clinica civil pelo Exmo. Snr. Dr. PAULA BUARQUE, clinico em Petropolis. A tecnica seguida consistiu em empregar no mesmo individuo em um dos antebraços a tuberculina tratada pelas substancias acima referidas e em outro antebraço a tuberculina testemunha. Só se utilisava como tuberculina testemunha a que era preparada com a mesina cultura que servira para ser obtida a tuberculina saturada pelos lipoides.

Os resultados forain concordes na experimentação: a tuberculina saturada por lipoides não determinava reaçũo ou esta era fugaz en:quanto que as reações testemunhas foram sempre nitidas.

As series experimentaes feitas em grande numero de cobaias não nos permitiram conclusões seguras, pela inconstancia dos resultados.

\section{Natureza da ligação tuberculina-lịpoi- des.}

Pelo exposto se vê que, por qualquer principio, fisico ou quimico, se dá a ligação e provavel neutralização, ou impedímento de acção, dos venenos do virus por influencia direta exercicia pelas substancias lipoides (principalmente colesterina e lecitina). Será essa ligação de natureza quimica, ou comı. nos parece mais provavel, representará ela um fenomeno de adsorpção?
A diversidade da constituição quimica entre a colesterina (alcool) e a lecitina (fosfatide) fala em favor da segunda hipotese; comtudo, quer em um quer em outro caso, não ha verdadeiramente neutralisação, no sentido quimico (acido contra base), nem tão pouco destruiç̧ão do poder hipersensibilisante daqueles toxicos. A ligação (fosfatide-tuberculina ou alcool-tuberculina) se mostra frouxa, em certos casos dissociavel, permitindo sua inoculação que os fenomenos de hipersensibilidade se possam manifestar.

Algumas vezes mesmo parece haver um aumento do poder toxxico não obstante se verificar a fixação dos venenos com substancias ricas em lipoides, como sucedeu con a substancia nervosa em mãos de GUILLAIN, e LAROCHE. A explicação desses fatos antagonicos é entretanto, razoavel, desde que nos lembremos ser uma propriedade dos lipoides agirem eles como ativadores de lisinas e de venenos.

Resuita porém de nossa observação que a tuberculina tratada en determinadas condişöes pela lecitina e pela colesterina, pelos lipoides da bile, e pelos lipoides $e$ outros principios mal definidos do oleo de figado de baialhau se mostra com suas propriedades hipersensibilisantes atennadas, de modo a poder ser empregada cm serie terapeutica sem receio de fenomenos reacionais prejudiclais, conservando entretanto projriedades imunisantes $e$ curativas.

Decorre essa afirmação do fato de termos, por mais de um ano, empregado tuberculina assim preparada, com fins terapeuticos, e m casos de contra-indicação segura (formas conjestivas, febris, de lesões pulmonares extensas) sem motivo de arrependimento e antes sim nos louvando de seu emprego, pelas melhoras ortidas pelos pacientes.

A tuberculina assim preparada, se aproxima por suas propriedades da E. B. K., pois que pela tecnica segnida, se prodnz a desagregação dos corpos bacilares, a destruição da carapaça dos bacilos com a consequente libertação de endotoxinas e de granulações mais o:ı menos alteradas em sua fórma. $A$ sua reabsorpção por via hipordcmica é perfeita. 
Ação direta dos lipoides sobre os bacilos.

Ação não menos interessante é a exercida pelos lipoides diretamente sobre os corpos bacilares, atacando sua carapaça cerea e desagregando as granulações.

Em 1909 tivemos a oportunigade de verificar a existencia, de isolar e de estudar um principio encontrado no pús de narureza tubercutosa que ajindo como fermento dissolvia os bacilos, libertando as granulações. Contemporaneamente observações idcnticas eram feitas por FIESSINGER e BERGEL que assim confirmavam a nossa experimentação. Essa mesma ação pode ser exercida por lipoides isoladamente (colesterina, lecitina), ou em misturas complexas como na bile e no oleo de figado de bacalhau.

A quimica complexa deste ultimo corpo não permite ainda, que de modo seguro se possa atribuir a qualquer dos seus constituentes a ação desintegrante por ele exercida sobre os corpos bacilares. Parece entretanto ser essa propriedade devida a varios de seus constituintes, taes como o colesterol e diferentes acidos graxos não saturados, sob a forma de esteres, como verificaram MILLER e MILDRED POWELL (cit. por MILLER) e OWEN-WILLANS e FORSYTH estudando a ação do oleo de balea e do oleo de figado de bacalhau snbre culturas e emulsões de bacilos de tuberculose.

\section{Como explicar a ação atenuadora dos lipoides sobre as toxinas.}

Como entretanto poderá ser explicada a ação atenuadora dos lipoides sobre as toxinas e endotoxinas bacilares? É fato fóra de duvida que a reação hipersensibilisante é uma reação originariamente celular.

Compreende-se, pois, haver necessidade de incorporação do toxico á intimidade dos constituintes da celula para que a reação se produza. Quer a consideremos como produto de ação diastasica, olhada sob o ponto de vista estrictamente quimico (desdobramento e hidrolise até redução a compostos menos complexos) quer a reconheçamos como de- rivante de atos bio-fisicos (coloides eletricos) o que é verciade adquirida é que as substancias lipoides exercem ação preponderante no quimismo vital, se acreditando mesmo (IVAR BANG op. cit.), ser seu papel muito mais importante que o exercido pelos albuminoides. Ainda mais, tudo faz crer que as ligações entre os corpos estruturais da unidade viva sejam tão estreitas que não se possa compreender a organisação plasmatica e nuclear da celula como resultado de elementos heterojenos e sim como complexo onde esses corpos existam unidos por afinidades intimas. As lecito-albuminas já deixam isto entrever. Sem que se tenha podido, até hoje, dar uma demonstração cabal, observaçôes diversas tendem a provar a veracidade dessa hipotese. Sabe-se com efeito, não ser possivel a veriflcação direta microquimica e indiretamente se conhece grandes correlações entre os lipoides e os fermentos, cuja ação sinerjica se confunde.

Isso verifiicou LAPIDUS (cit. por BANO) estudando o estado da diastase do sôro de sangue, antes e depois de ajitar o sôro com eter, constatando uma diminuição do poder diastasico após o tratamento pelo eter. E' que provavelmente, o eter retirava uma substancia ativante. A adição de leticina ativou novamente este sôro emquanto que junta ao sôro arterioımente determinava um impedimento. Por isso admite BANG, (op. cit.) que os lipoides do sôro podem influir sobre o processo diastasico de modo sensivel e que até mesmo o governam.

Relativamente á constituição anatomica celular os lipoides ocupam o primeiro lugar determinando a nutrição da unidade viva; na estrutura da membrana, coordenando os fenomenos de osmose, na intimidade do plasma e da substancia nuclear, presidindo aos atos fermentativos de nutrição e de oxydação (respiração celular).

\section{Conclusões.}

\section{Resumo.}

Assim em resumo pensamos que a hipersensibilidade na infeção tuberculosa é a 
expressão duma reaçãc celular, autonoma e individual, consequente á agressão brusca e á destruição (dijestão) incompleta dos toxicos bacilares (proteinas, globulinas e lipoides), em combinação intima ou isoladamente; a adição aos toxicos bacilares de lipoides diversos (cholesterina, lecitina, esters) e principios mal definidos existentes no oleo de figado de bacalhau, atenua a sna função hipersensibilisante porque torna esses toxicos mais facilmente incorporaveis á celula sensivel por adsorpção da substancia toxica ao lipoide. Esses corpos penetram assim no in- terior das celulas levando comsigo ativadores dos processos enzimaticos que não so favorecem uma elaboração dijestiva mais perfeita como ainda uma melhor produção de anticorpos. O aparecimento de pequenas modalidades reacionarias no decurso duma inmunisação ativa contra os antijenos saturados por lipoides mostra a necessidade dum processo de desintegração para que a função toxica se manifeste.

Dezembro 1917. 


\section{$152-$ \\ Bibliografia}

ALBAHARY, J. M. 1914 Ueb. einen Tuberkuloseimpfstoff. Muench. med. Wochens :dr. Jnni, p. 1385.

BANG, IVAR

BERGEL

BERTARELLI \& DATTA 1910

BESREDKA

BEYER

BRUSCHETTINI

FIESSINGER, NOEL \& MARIE, PIERRE

FONTES, A. C.

GOMES, ALCANTARA

LAROCHE

LEMOINE

LESCHKE, ERHCH

LOEWENSTEIN

MILDRED POWELL

MILLER, A. H.

OWEN WILLIAMS \& FORSYTH

PICKERT

SPENGLER

THIELE \& EMBLETON

WHITE, BENJAMIN
1911 Chemie und Biochemie der Lipoide.

1909 Fettspaltendes Ferment in den Lymphozyten Muecnh. med. Wochenschr. Jahrg. 56 No 2.

Experimentelle Untersuchungen ueb. Antituberculin.

Centralbl. f. Bakt. Orig. Bd. 58. Hft. 2.

1917 Theorie de l'anaphylaxie.

Buil. Inst. Pasteur. T. 15 No 14.

1910 Ueb. Beziehungen des Lecithins zum Tuberkelbazillus und, desses Produkten.

Centralbl. Bakt. Orig. Bd. 56 Hft. 2 p. 160.

1912 Communicação ao Congresso de Roma Abril de 1912.

1909 La lipase des leucocytes dans les exsudats.

C. R. Soc. Biologie T. 68 No 26.

1909 Estudos sobre a tubercuios?.

Mem. Inst. Oswaldo Cruz, Vol. 1.

1914 These inaugural-Dezembro.

1910 Fixation de la tuberculine par la substance nerveuse.

C. R. Soc. Biologie p. 220.

1911 Des résultats éloignés obtenus dans la tuberculosc par l'action thérapeutique des lipoides biliaires.

Bull. \& Mem. Soc. med. Hop. Paris Ser. 3, T. 32 p. 638.

1912 Tuberkuloeseimmunitat und Immuntherapie, c. in Internat. Centralbl. f. d. ges. Tnberkulose-Forschung. Jahrg. 6. p. $499 \& 563$.

1910 Ueb. Antikoerper bei Tuberkulose.

Zeits. f. Tuberkulose Bd. 15.

1913 Influence of unsaturadted fatty acids on the tubercle Bacillus.

Liverpoot med.-cir. Journ. Vol. 33 p. 213 cit. por MILLER.

1916 Reactions of tubercle bacillus to sperm-oil. Jouru. of Pathology \& Bact. Vol. 20 No 4.

1909 The influence of the unsaturatep fatty acids in tuberculosis. Brit. med. Journ. Vol. 2 p. 1120.

1909 Ueb. das gesetzmaessig Auftreten von Tuberkulinantikoerpern in Laufe der spezifischen Behandlung $u$. seine Bedeuting f. die Therapie.

Deut. med. Wochenschr. S. 1514 (cit. por LESCHKE).

1909 Ueber I. K. Behandlung.

Deut. med. Wochenschr.

1915 Lipoids in immunity (II).

Journ. of. Pathol. x Bact. Vol. 19 No 3 p. 349.

1914 Some experiments in anaphylaxis with the lipoids of the tubercle Bacillus.

Journ. of. med. Research. Vol. 30. 
WHITE, BENJAMIN \& 1912 The action of certain products obtaines from the tubercle AVERY, OSWALD Bacillus.

Journ. of. med. Research. Vol. 26.

WHITE \& ORAHAM 1909 Studies in the action of sera on tuberculin cutaneous rcaction.

Journ. of. med. Research Vol. 21. 


\section{4}

\section{Explicação da estampa 32.}

Pig. 1-Reaparecimeuto da reação tuberculinica (V. Pirquet) dous mezes depois da reação diagnostica ter cessado. Esta reação reapareceu no decurso do tratamento tuberculinico do paciente em seguida a uma faze reacionaria.

Fig. 2 e 3-Lesర̃es psorisiacas que se apresentaram no curso da reação havida. 

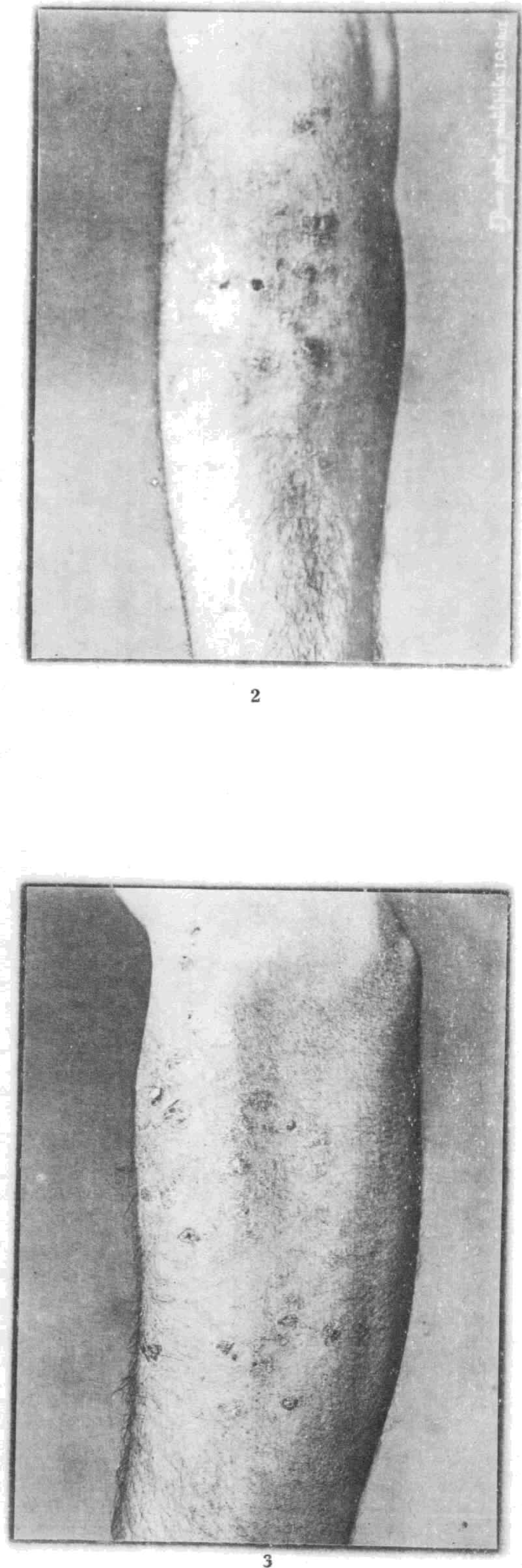